\title{
School attainments in children with congenital hypothyroidism detected by neonatal screening and treated early in life
}

\author{
Stefania Bargagna, Daniela Dinetti, Aldo Pinchera ${ }^{1}$, Mara Marcheschi, Lucia Montanelli ${ }^{1}$, \\ Silvano Presciuttini ${ }^{2}$ and Luca Chiovato ${ }^{1}$ \\ Stella Maris Scientific Institute, Institute of Developmental Neurology, Psychiatry and Educational Psychology, ${ }^{1}$ Department of Endocrinology and \\ ${ }^{2}$ Department of Human, Environmental and Genetic Sciences, University of Pisa, Pisa, Italy \\ (Correspondence should be addressed to L Chiovato, Department of Endocrinology, Ospedale di Cisanello, Via Paradisa 2, 56124 Pisa, Italy)
}

\begin{abstract}
Objective: Evaluation of school attainments in children with congenital hypothyroidism $(\mathrm{CH})$ detected by neonatal screening and treated early in life.

Patients and methods: Text comprehension, mathematics, reading, writing and verbal and spatial memory, as indices of school learning, were evaluated in nineteen 5- to 10-year-old children with $\mathrm{CH}$ attending nursery or elementary school. L-Thyroxine substitution (starting dose $8-10 \mu \mathrm{g} / \mathrm{kg}$ body weight per day) was initiated at a mean age of $30 \pm 10$ days of life. The control group included 298 unaffected children matched with the $\mathrm{CH}$ children for age and school grade. Thirty per cent of controls were classmates of $\mathrm{CH}$ children. Intelligence quotients (IQ), language performances and motor development were evaluated in $\mathrm{CH}$ children at age 5 years, and were related to their school attainments. School performances of $\mathrm{CH}$ children were also compared with their neonatal serum thyroxine $\left(\mathrm{T}_{4}\right)$ concentration, and with the social-cultural level of the family.

Results: Four out of $19(21 \%)$ children with CH, 3 in the nursery and 1 in the elementary school, displayed a generalized learning disorder. Symbol copy, geometric copy, phrase repetition, dictation writing and spontaneous writing were particularly defective in nursery school $\mathrm{CH}$ children, while orthographic error recognition was defective in elementary school $\mathrm{CH}$ children. School learning disorders in $\mathrm{CH}$ children were significantly correlated with a borderline-low IQ, poor language performances and a low social-cultural level of the family, but not with motor skills or neonatal $\mathrm{T}_{4}$ concentration.

Conclusion: School attainments of early treated $\mathrm{CH}$ children were within the normal range in most affected cases. However, about $20 \%$ of $\mathrm{CH}$ children, most of them attending nursery school, showed a generalized learning disorder. Low IQ scores and poor language performances at age 5 years were associated with defective learning, mainly in $\mathrm{CH}$ children living in a poor social-cultural environment. In this subset of $\mathrm{CH}$ children, prompt initiation of speech and psychomotor rehabilitation therapy is recommended in order to prevent subsequent school learning disorders.
\end{abstract}

European Journal of Endocrinology 140 407-413

\section{Introduction}

Several studies have reported normal global neuropsychological development in children with congenital hypothyroidism $(\mathrm{CH})$ detected by neonatal screening and treated early in life (1-3). However, some of these $\mathrm{CH}$ children have subtle impairments in language abilities (3-5), neuromotor skills (5-7), behaviour $(8,9)$ and cognitive performances $(4,10-18)$. Such impairments might adversely affect school learning. Investigations of school attainments in $\mathrm{CH}$ children treated early in life have produced controversial results $(19,20)$. School performances were found normal by the New England Congenital Hypothyroidism
Collaborative (19), but mild non-verbal learning disability (20) and mild impairment in educational attainments (21) have been found in other series of early treated $\mathrm{CH}$ children.

The present study was designed to assess school performances in a group of $\mathrm{CH}$ children detected by neonatal screening and attending nursery or elementary school when 5-10 years old. Comprehension, arithmetic, reading, writing, orthographic error recognition (OER) and verbal and spatial memory were evaluated. Learning attainments at school were related to the results of cognitive, language and motor tests performed at age 5 years. We also studied the influence on learning achievements of the severity of neonatal 
hypothyroidism and of the social-cultural level (SCL) of the family.

\section{Materials and methods}

\section{Patients and controls}

The $\mathrm{CH}$ group included $19 \mathrm{CH}$ children (13 females, 4 males) detected by neonatal screening. All $\mathrm{CH}$ children were born at term, and none of them suffered from other perinatal disease. All children were born in iodine-sufficient urban areas of Tuscany. L-Thyroxine (L-T $\left.\mathrm{T}_{4}\right)$ substitution therapy $(8-10 \mu \mathrm{g} / \mathrm{kg}$ body weight (BW) per day) was initiated at a mean $( \pm \mathrm{SD})$ age of $30 \pm 10$ days (range 17-50, median 31 days). Before starting therapy, serum $\mathrm{T}_{4}$ concentration was $\leq 3 \mu \mathrm{g} / \mathrm{dl}$ $(\leq 40 \mathrm{nmol} / \mathrm{l})$ in $13 \mathrm{CH}$ children and $>3 \mu \mathrm{g} / \mathrm{dl}$ $(>40 \mathrm{nmol} / \mathrm{l}) \quad(\mathrm{range} \quad 3.5-9.0 \mu \mathrm{g} / \mathrm{dl}, 45-116 \mathrm{nmol} / \mathrm{l})$ in the remaining 6 children. Follow-up examination, including measurements of serum free thyroid hormones $\mathrm{T}_{4}$ and tri-iodothyronine and thyrotrophin (TSH), was carried out every 3 months in the first year of life, and every 3-6 months thereafter. The initial dose of $\mathrm{L}_{-} \mathrm{T}_{4}$ was adjusted taking into account the serum concentration of free thyroid hormones and TSH, with the aim of maintaining serum TSH in the normal range. Any elevation in the serum TSH concentration was promptly corrected by increasing the dose of $\mathrm{L}-\mathrm{T}_{4}$.

\section{Evaluation of school learning attainments}

Four CH children (DS, GF, SS, BM), aged 5 years, attended the nursery school, and 15, aged 6-10 years, attended the elementary school, three (CB, NF, FB) in the 1st grade, three (ET, NM, AS) in the 2nd grade, six (NB, EB, FG, PL, MG, AD) in the 3rd grade and three (DD, AF, SP) in the 4th grade class.

The following learning tests were administered to nursery school children: (i) school maturity test (22) (subtests: symbol comparison, symbol copy, picture connection for semantic aspects, quantity, picture choice, picture copy, geometric picture copy, phrase repetition, summary, picture description); (ii) alphabetic knowledge evaluation test (23) (independent letter recognition, presented letter recognition, letter copy, postponed letter copy, dictated writing); (iii) spontaneous writing evaluation test (23); and (iv) digit span verbal memory and cube spatial memory tests (24).

Elementary school children received the following learning tests: (i) comprehension test (25); (ii) objective arithmetical performance test (26); (iii) reading and writing tests; (iv) OER test (23); and (v) digit span verbal memory and cube spatial memory tests (24).

Informed consent was obtained from parents, teachers and the school board. Anonymity was maintained. An Italian language methodology was used for language tests. School learning assessment took into account current Italian school curricula and was calibrated for Italian children.

The control group included 298 children (141 females, 157 males). Sixteen attended the nursery school and 282 the elementary school, 51 in the 1st grade, 50 in the 2 nd grade, 81 in the 3 rd grade and 100 in the 4th grade class. Thirty per cent of controls included classmates of $\mathrm{CH}$ children, the remaining control children attended paired classes of the same grade.

\section{Evaluation of cognitive and neuro-motor development}

$\mathrm{CH}$ children were evaluated at age 5 years with the Griffiths intelligence scale (27), the modified Touwen neuro-motor examination (28) and several language tests (Bortolini-Fanzago language articulation test (29), language comprehension and spontaneous speech tests (30)). The following items were evaluated: intelligence quotient (IQ), language performance (language) and motor skills (motor). According to the DSM-IV (American Psychiatric Association Diagnostic and Statistical Manual of Mental Disorders) (31), a semiquantitative score $(0-2)$ was attributed to language performances $(0=$ expressive language disorder with simplified/limited varieties of grammatical structures and phonological errors; $1=$ phonological disorder; $2=$ normal language $)$ and motor skills $(0=$ coordination disorder with clumsiness and delays in achieving developmental motor milestones; $1=$ mild clumsiness; 2 = normal motor development).

The SCL of the family was assessed taking into account the parents' school-leaving qualifications, their current job and social position. A semiquantitative score $(0-3)$ was assigned to SCL, with 0 indicating the worst and 3 indicating the best.

\section{Data analysis and statistics}

Differences in learning achievements between $\mathrm{CH}$ children and controls attending nursery school were analyzed by $t$-test (two-tail). A z-score (deviation from the control mean expressed in units of standard deviation) was calculated for each performance of $\mathrm{CH}$ children. For elementary school children we calculated individual z-scores for each performance compared with control children in the same grade. We thus obtained a table with 7 columns (corresponding to performances) and 15 rows (corresponding to individual patients). The column means were used to test the hypothesis that a specific area was generally defective in $\mathrm{CH}$ children, whereas the row means were used to test for the existence of overall performance heterogeneity among $\mathrm{CH}$ children. The significance of the values observed was obtained by comparison with a normal density having zero mean and S.D. $=1 / n$ ( $n$ being the number of averaged scores). Pearson 
correlation coefficients were computed to evaluate relationships between learning achievements and each of the following variables: intelligence (IQ), language, motor, SCL of the family, pretreatment serum $\mathrm{T}_{4}$ concentration and age at starting treatment.

\section{Results}

\section{Nursery school children}

Table 1 shows the results of learning tests in the $4 \mathrm{CH}$ children and in the 16 controls. $\mathrm{CH}$ children had significantly lower scores $(P<0.01)$ in five tests: symbol copy, geometric copy, picture copy, phrase repetition and spontaneous writing. Although at a lower significance level $(P<0.05)$, $\mathrm{CH}$ children had worse scores in four additional tests: independent recognition, presented letter recognition, dictation writing and verbal memory.

In order to measure the global learning performance of individual $\mathrm{CH}$ children, we calculated the z-score of single tests, and then the mean of z-scores of all tests for each $\mathrm{CH}$ child (Table 2). Three out of four $\mathrm{CH}$ children had significantly lower performances compared with the controls, and two of them (DS, SS) belonged to the lower 0.002 tail of the population.

\section{Elementary school children}

For each learning test of individual $\mathrm{CH}$ children we calculated a z-score, compared with the mean performance observed in grade-matched control children.
Results are summarized in Table 3 with 7 columns (performances in learning tests) and 15 rows (individual $\mathrm{CH}$ children).

The grand-total mean $(\mathrm{z}=-0.090)$ was not significantly different from zero $(P=0.46)$. However, one $\mathrm{CH}$ child $(\mathrm{PL})$ had a significantly lower $(P<0.05)$ mean $\mathrm{z}$-score. The analysis of mean z-scores (means of performances in all $\mathrm{CH}$ subjects) indicated that OER (mean $\mathrm{z}=-1.768, \mathrm{P}<0.038$ ) is a defective area, while other performances are within the normal range.

The frequency distribution of z-scores of all learning performances in $\mathrm{CH}$ children did not show gross deviation from the $\mathrm{z}$-score distribution of normal children.

\section{Distribution of learning performances among all CH children}

CH children attending nursery and elementary school in any class grade were grouped together taking into account their individual mean z-scores (Fig. 1). Three $\mathrm{CH}$ children attending the nursery school (DS, SS, BM) had mean z-scores lower than 2 S.D. from the mean of controls.

\section{Correlation of individual learning performances with other variables}

Table 4 shows the mean z-scores of learning tests in individual $\mathrm{CH}$ children compared with $\mathrm{IQ}$, language and motor scores evaluated at age 5 years, with the SCL of the family, with neonatal serum $\mathrm{T}_{4}$ levels, and

Table 1 Results of learning tests in the 4 children with $\mathrm{CH}$ attending nursery school and in 16 control children.

\begin{tabular}{|c|c|c|c|c|}
\hline \multirow[b]{2}{*}{ Performances } & \multicolumn{2}{|c|}{ Mean ( \pm S.D.) } & \multirow[b]{2}{*}{$t$} & \multirow[b]{2}{*}{$\boldsymbol{P}$} \\
\hline & $\mathrm{CH}$ children & Controls & & \\
\hline \multicolumn{5}{|l|}{ School maturity test (22) } \\
\hline Total score & $21.25 \pm 5.19$ & $35.56 \pm 6.89$ & 2.732 & 0.014 \\
\hline Symbol comparison & $3.25 \pm 2.06$ & $4.56 \pm 1.40$ & 1.078 & NS \\
\hline Symbol copy & $0.75 \pm 0.96$ & $4.38 \pm 1.41$ & 3.477 & 0.003 \\
\hline Picture connection (semantic) & $3.75 \pm 2.63$ & $5.63 \pm 1.09$ & 1.191 & NS \\
\hline Quantity & $3.25 \pm 4.72$ & $3.88 \pm 2.99$ & 0.245 & NS \\
\hline Picture choice & $1.75 \pm 2.00$ & $2.38 \pm 1.15$ & 0.549 & NS \\
\hline Picture copy & $2.00 \pm 1.15$ & $3.69 \pm 1.40$ & 2.025 & 0.058 \\
\hline Geometric copy & $0.25 \pm 0.50$ & $2.25 \pm 1.81$ & 4.600 & 0.001 \\
\hline Phrase repetition & $0.25 \pm 0.50$ & $2.13 \pm 1.02$ & 3.589 & 0.002 \\
\hline Summary & $3.50 \pm 1.91$ & $3.94 \pm 2.43$ & 0.418 & NS \\
\hline Picture description & $2.56 \pm 1.00$ & $2.94 \pm 1.24$ & 0.768 & NS \\
\hline \multicolumn{5}{|c|}{ Alphabetic knowledge evaluation test (23) } \\
\hline Independent recognition & $3.25 \pm 4.55$ & $15.94 \pm 7.24$ & 2.732 & 0.014 \\
\hline Presented recognition & $5.00 \pm 1.83$ & $15.06 \pm 0.87$ & 2.607 & 0.018 \\
\hline Copy & $19.00 \pm 2.63$ & $20.69 \pm 1.03$ & 1.460 & NS \\
\hline Postponed copy & $18.75 \pm 4.24$ & $20.50 \pm 7.22$ & 1.125 & NS \\
\hline Dictation writing & $4.00 \pm 5.74$ & $15.00 \pm 13.68$ & 2.864 & 0.010 \\
\hline Spontaneous writing & $3.50 \pm 1.00$ & $23.13 \pm 0.73$ & 3.452 & 0.003 \\
\hline Verbal memory & $3.25 \pm 0.50$ & $4.19 \pm 1.05$ & 2.462 & 0.024 \\
\hline Spatial memory & $2.50 \pm 5.97$ & $3.50 \pm 7.85$ & 1.554 & NS \\
\hline
\end{tabular}


with the age of life (days) at starting $\mathrm{L}_{-} \mathrm{T}_{4}$ treatment. IQ scores of $\mathrm{CH}$ children were within the normal range (85-133). Language was normal in six $\mathrm{CH}$ children, while mild or specific disorders were observed in nine

Table 2 Mean scores and mean z-scores of school learning tests of children with $\mathrm{CH}$ attending nursery school.

\begin{tabular}{lccc}
\hline CH children (initials) & Mean & $\mathbf{z}$ & $\boldsymbol{P}$ \\
\hline DS & 0.269 & -3.235 & 0.001 \\
CF & 0.491 & -1.350 & 0.089 \\
SS & 0.319 & -2.814 & 0.002 \\
BM & 0.389 & -2.217 & 0.013 \\
\hline
\end{tabular}

and four children respectively. Motor was unaffected in nine $\mathrm{CH}$ children, while a mild or marked motor disorder occurred in seven and three $\mathrm{CH}$ children respectively. Neonatal serum $\mathrm{T}_{4}$ concentration was $\leq 3 \mu \mathrm{g} / \mathrm{dl}$ in $13 \mathrm{CH}$ children and $>3 \mu \mathrm{g} / \mathrm{dl}$ in the remaining 6 . The SCL of the family was high (3) in two $\mathrm{CH}$ children; medium-high (2) in five, mediumlow (1) in seven and low (0) in five. Table 5 shows the correlation coefficients between the mean z-scores of learning tests in $\mathrm{CH}$ children and the other variables. There was a significant correlation of learning z-scores with IQ $(r=0.67, P<0.002)$, language $(r=0.55$, $P<0.02)$ and the SCL of the family $(r=0.46$, $P<0.05)$. No significant correlation was found with

Table 3 Learning tests of children with $\mathrm{CH}$ attending elementary school. For each learning test of individual $\mathrm{CH}$ children we calculated a z-score, compared with the mean performance observed in grade-matched controls. Results are summarized with 7 columns (performances in learning tests) and 15 rows (individual $\mathrm{CH}$ children). The grand-total mean $(z=-0.090)$ was not significantly different from zero. One $\mathrm{CH}$ child $(\mathrm{PL})$ had a significantly lower $(P=0.05)$ mean z-score. The analysis of mean $z$-scores (means of performances in all $\mathrm{CH}$ children) indicated that $\mathrm{OER}$ is a defective area, while other performances are within the normal range.

\begin{tabular}{|c|c|c|c|c|c|c|c|c|c|}
\hline $\begin{array}{l}\text { CH children } \\
\text { (initials) }\end{array}$ & Comprehension & Arithmetic & Reading & Writing & OER & $\begin{array}{l}\text { Verbal } \\
\text { memory }\end{array}$ & $\begin{array}{l}\text { Spatial } \\
\text { memory }\end{array}$ & $\begin{array}{c}\text { Mean } \\
\text { z-score }\end{array}$ & $P$ \\
\hline CB & -1.391 & 0.248 & -0.159 & -0.175 & -0.023 & 0.096 & 0.123 & -0.484 & 0.314 \\
\hline NF & 0.746 & -0.732 & -0.125 & -0.363 & -0.637 & 0.096 & 0.123 & -0.526 & 0.299 \\
\hline FB & 1.173 & 1.718 & -0.169 & 1.201 & 1.205 & 0.096 & 0.123 & 2.021 & 0.978 \\
\hline ET & -0.225 & -0.753 & 0.819 & -0.930 & -0.905 & 1.438 & 0.074 & -0.182 & 0.428 \\
\hline NM & -0.225 & -0.577 & -0.092 & 0.680 & -0.905 & 0.261 & 0.074 & -0.296 & 0.384 \\
\hline AS & 0.329 & 0.483 & -0.168 & 0.680 & -0.905 & 1.438 & 3.400 & 1.987 & 0.977 \\
\hline NB & 0.824 & -0.452 & 0.424 & -0.591 & 0.213 & -1.366 & 2.122 & 0.444 & 0.671 \\
\hline EB & 0.824 & 0.671 & -0.271 & -0.166 & 0.741 & -0.489 & 0.760 & 0.783 & 0.783 \\
\hline $\mathrm{FG}$ & 0.096 & -0.115 & -0.558 & 0.685 & -0.315 & -0.489 & 0.760 & 0.024 & 0.510 \\
\hline$P L$ & -0.147 & 0.446 & -1.402 & -1.441 & -2.956 & 0.387 & 0.760 & -1.645 & 0.050 \\
\hline$M G$ & 0.339 & -0.340 & -0.375 & 0.260 & -0.844 & -1.366 & -0.601 & -1.106 & 0.134 \\
\hline$A D$ & -0.147 & 1.008 & 0.004 & 0.260 & -0.844 & -0.489 & -0.601 & -0.306 & 0.380 \\
\hline DD & 0.824 & 0.692 & -0.152 & -0.108 & 0.674 & 0.247 & - & 0.889 & 0.813 \\
\hline$A F$ & -1.958 & -0.025 & -0.007 & 0.612 & -2.021 & 0.247 & 0.587 & -0.969 & 0.166 \\
\hline SP & -1.262 & -0.466 & -0.225 & 0.612 & 0.674 & -1.386 & -0.508 & -0.968 & 0.166 \\
\hline Mean z-score & -0.051 & 0.466 & -0.634 & 0.184 & -1.768 & -0.330 & 1.923 & -0.090 & 0.464 \\
\hline Mean $P$ & 0.480 & 0.679 & 0.263 & 0.573 & 0.038 & 0.371 & 0.973 & 0.464 & - \\
\hline
\end{tabular}

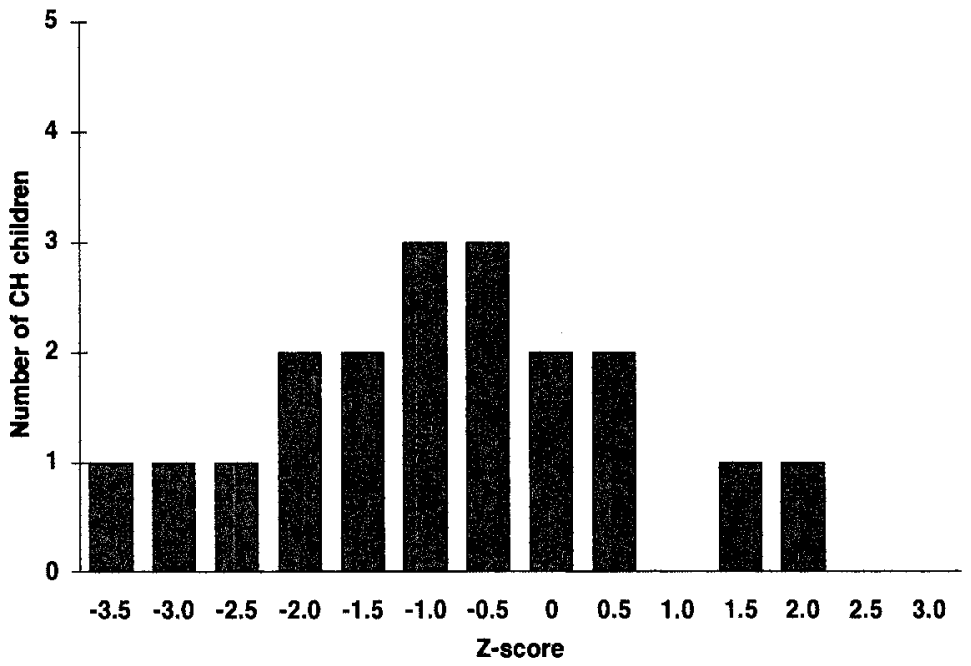

Figure 1 Distribution of mean z-scores of learning tests in children with $\mathrm{CH}$ attending nursery or elementary school in any class grade. 
Table 4 Mean z-scores of learning tests (Learn) in individual children with $\mathrm{CH}$ compared with IQ, language (Lang) and motor skills (Motor) scores evaluated at 5 years of age, SCL level of the family, neonatal serum $\mathrm{T}_{4}$ concentration and the age of life (days) at starting $\mathrm{L}-\mathrm{T}_{4}$ treatment.

\begin{tabular}{|c|c|c|c|c|c|c|c|}
\hline $\begin{array}{l}\text { CH children } \\
\text { (initials) }\end{array}$ & Learn & $\mathrm{IQ}$ & Lang & Motor & $\begin{array}{c}\mathbf{T}_{\mathbf{4}} \\
(\mu \mathrm{g} / \mathrm{dl})\end{array}$ & SCL & Days \\
\hline DS & -3.235 & 85 & 0 & 0 & 7 & 0 & 36 \\
\hline SS & -2.814 & 95 & 0 & 1 & 1 & 1 & 20 \\
\hline BM & -2.217 & 100 & 1 & 2 & 1 & 1 & 21 \\
\hline $\mathrm{PL}$ & -1.645 & 97 & 1 & 1 & 6 & 0 & 46 \\
\hline GF & -1.350 & 91 & 0 & 0 & 1 & 1 & 23 \\
\hline MG & -1.106 & 104 & 1 & 1 & 1 & 0 & 30 \\
\hline $\mathrm{AF}$ & -0.969 & 108 & 2 & 2 & 2 & 0 & 23 \\
\hline SP & -0.968 & 103 & 1 & 2 & 5 & 1 & 17 \\
\hline NF & -0.526 & 95 & 1 & 1 & 1 & 1 & 24 \\
\hline CB & -0.484 & 113 & 2 & 2 & 1 & 3 & 19 \\
\hline$A D$ & -0.306 & 99 & 1 & 1 & 1 & 2 & 50 \\
\hline NM & -0.296 & 97 & 0 & 0 & 1 & 3 & 31 \\
\hline ET & -0.182 & 123 & 2 & 2 & 9 & 1 & 36 \\
\hline $\mathrm{FG}$ & 0.024 & 103 & 1 & 1 & 3 & 1 & 32 \\
\hline NB & 0.444 & 108 & 2 & 2 & 1 & 2 & 32 \\
\hline EB & 0.783 & 128 & 2 & 2 & 1 & 2 & 50 \\
\hline DD & 0.960 & 133 & 1 & 1 & 4 & 0 & 23 \\
\hline AS & 1.987 & 103 & 2 & 2 & 3 & 2 & 34 \\
\hline FB & 2.021 & 122 & 1 & 2 & 1 & 2 & 40 \\
\hline
\end{tabular}

\begin{tabular}{|c|c|c|}
\hline & $r$ & $P$ \\
\hline IQ & 0.671 & $<0.002$ \\
\hline Lang & 0.547 & $<0.02$ \\
\hline SCL & 0.459 & $<0.05$ \\
\hline Motor & 0.439 & NS \\
\hline $\mathrm{T}_{4}$ & -0.319 & NS \\
\hline Days & 0.300 & NS \\
\hline
\end{tabular}

neonatal serum $\mathrm{T}_{4}$ concentration $(r=-0.32$, NS) and the age in days at starting $\mathrm{L}_{-} \mathrm{T}_{4}(r=0.30$, NS). Global learning performances did not significantly differ in $\mathrm{CH}$ children with neonatal $\mathrm{T}_{4} \leq 3 \mu \mathrm{g} / \mathrm{dl}$ compared with those with a neonatal $\mathrm{T}_{4}>3 \mu \mathrm{g} / \mathrm{dl}$.

\section{Discussion}

Learning disorders are manifested as significant difficulty in acquiring and using the skills of listening, oral production, reading, writing, reasoning and mathematics (32). Global learning difficulty patterns usually present a less severe picture compared with selective learning disorders (dyslexia, dysgraphia, dyscalculia) and are usually transient, provided that appropriate teaching support is undertaken. In Italy, the prevalence of learning disorders in the whole child population is around $3.4 \%$ (33). This prevalence does not include children with relational pathologies or sensorial deficits. School learning is dependent on the integrity of the basic neuropsychological mechanisms that are anchored to the neurobiological substrate. In this regard, phonological and morphosyntactic aspects of speech, and fine and gross motor skills are particularly relevant for the acquisition of reading, writing and arithmetic. The SCL of the family is an additional factor influencing school learning (34). An educated family background and continuous stimulation by parents can make progress at school easier, and can favour learning.

In some follow-up programmes for $\mathrm{CH}$, global IQs of children treated early in life do not differ from those of control children $(1,3)$. Other follow-up studies report a mild decrease in global IQs compared with controls (10-18). Differences in motor and psychometric subtests have also been reported. These include language deficits (4-6), lower scores in tests involving motor speed, balance and fine or gross motor functions (5-7), and reduced verbal and memory abilities (16).

Elementary school performances, both global and in different subtests, were found normal by the New England Congenital Hypothyroidism Collaborative (19). However, Rovet et al. (20) reported mild non-verbal learning disability in some children with $\mathrm{CH}$. Recently, less satisfactory scores for educational attainments, behaviour and motor skills were reported in $\mathrm{CH}$ children with more severe neonatal hypothyroidism $\left(\mathrm{T}_{4} \leq 3 \mu \mathrm{g} / \mathrm{dl}, 40 \mathrm{nmol} / \mathrm{l}\right)$ compared with less affected $\mathrm{CH}$ children (neonatal $\mathrm{T}_{4}>3 \mu \mathrm{g} / \mathrm{dl}, 40 \mathrm{nmol} / \mathrm{l}$ ) (21). 
While differences for reading were small, deficits in mathematics were statistically significant (21).

In the present study a more detailed analysis of learning attainments was performed by evaluating not only reading and mathematics, but also abilities in writing, OER and verbal and spatial memory. Four $(21 \%) \mathrm{CH}$ children (three attending nursery school and one elementary school) experienced a learning disorder. This prevalence was greater than that expected in the general Italian child population. Learning disorders were more prevalent and marked in younger $\mathrm{CH}$ children attending nursery school. In these children symbol copy, geometric copy, phrase repetition and spontaneous writing were particularly defective. Independent letter recognition, presented letter recognition, dictation writing and verbal memory were less affected. The low number of children attending nursery school does not allow definitive conclusions to be drawn. It cannot be excluded that by pure coincidence our study grouped together cases with concomitant disadvantages due to severity of $\mathrm{CH}$ and low SCL family condition. As an alternative explanation it could be hypothesized that an improvement of learning performances does occur with increasing age in $\mathrm{CH}$ children. Indeed, global learning performances of older $\mathrm{CH}$ children attending elementary school did not significantly differ from those of control children. Only OER was significantly lower in $\mathrm{CH}$ children attending elementary school compared with controls.

Learning performances in the whole study group were significantly correlated with IQ and language scores at 5 years of age, and with the SCL of the family. $\mathrm{CH}$ children with learning disorders had borderlinelow IQ scores ranging from 85 to 100 , and severe to moderate language defects. A similar relationship with borderline-low cognitive level and poor language performances has been reported for learning disorders observed in the general population (35-38). A low SCL of the family also negatively affected learning attainments in our $\mathrm{CH}$ children. This may result from an insufficient supply of stimuli during the development or from difficulty in providing care for the child with resulting neglect in the affective-relational sphere (39).

The neonatal concentration of serum $\mathrm{T}_{4}$ before starting $\mathrm{L}_{-} \mathrm{T}_{4}$ replacement was apparently unrelated to subsequent school attainments in this group of $\mathrm{CH}$ children. Although in our $(18,40)$ and others' $(14,15$, $17,41,42)$ experience, a low neonatal $\mathrm{T}_{4}$ level is a risk factor for a defective neuropsychological development, in the present study the degree of neonatal thyroid hormone deficiency was not found to be a major variable influencing school learning. In this regard, our results do not completely agree with the recent observation that a low neonatal $\mathrm{T}_{4}$ is associated with less satisfactory scores for educational attainments (21). This might be due to the fact that in our study the two $\mathrm{CH}$ children (DS and PL) with a learning disorder but a neonatal $\mathrm{T}_{4}>3 \mu \mathrm{g} / \mathrm{dl}$ were brought up in families with a particularly low SCL.

In our $\mathrm{CH}$ children, substitution treatment was initiated at age $17-50$ days (median 31 days) with a starting dose of $\mathrm{L}_{-} \mathrm{T}_{4}$ ranging from 8 to $10 \mu \mathrm{g} / \mathrm{kg} \mathrm{BW}$ per day. Correction of thyroid function, as assessed by a total serum $\mathrm{T}_{4}$ concentration greater than $10 \mu \mathrm{g} / \mathrm{dl}$ (19), was achieved between 30 and 80 days of life. Higher doses of $\mathrm{L}_{-} \mathrm{T}_{4}$ (range 8.6-16.9, median $12.1 \mu \mathrm{g} / \mathrm{kg}$ BW per day) started at an earlier age (range 12-35, median 14 days), have been reported to prevent any psychomotor abnormality in $\mathrm{CH}$ children with severe $\mathrm{CH}$ assessed at 18 months of age (43). The question of whether the school attainments of $\mathrm{CH}$ children treated earlier and with a higher dose of $\mathrm{L}^{-\mathrm{T}_{4}}$ are entirely normal remains to be answered by the follow-up of this cohort of children.

In conclusion, our study indicates that the evaluation of IQ and language performances in $\mathrm{CH}$ children at the age of 5 years may alert one to the risk of subsequent occurrence of learning disorders. This is particularly true in $\mathrm{CH}$ children living in families with a low SCL. All $\mathrm{CH}$ children with borderline-low IQ and/or defective language should receive a careful neuropsychological observation associated with appropriate speech therapy and educational treatment in preschool years aimed at improving their school learning potential.

\section{Acknowledgements}

This work was supported by grants from the National Research Council (CNR Rome, Italy); Target Project: Biotechnology and Bioinstrumentation, Grant 91.01219, PF70; Target Project: Prevention and Control of Disease Factors (FATMA), Grant 93.00689, PF41; Target Project: Ageing, Subproject Gerontobiology, Grant 93.00437, PF40; EEC Stimulation ActionScience Plan Contract SC1-CT91-07007; Project: Prevenzione dei fattori di rischio nella salute maternofetale, sub-project: Studio dei fattori di rischio nella patogenesi delle forme congenite di ipotiroidismo e prevenzione dei fattori di rischio nella salute maternofetale (Istituto Superiore di Sanità, Roma), Italy. Project: Studio della fisiopatologia tiroidea (contratto Bracco).

\section{References}

1 New England Congenital Hypothyroidism Collaborative. Neonatal hypothyroidism screening: status of patients at 6 years of age. Journal of Pediatrics 1985107 915-918.

2 Illig R, Largo RH, Oin O, Torresani T, Rochiccioli P \& Larsson A. Mental development in congenital hypothyroidism after neonatal screening. Archives of Disease in Childhood 198762 1050-1055.

3 La Franchi S. Congenital hypothyroidism: a newborn screening success story? Endocrinologist 1994 4 477-486.

4 Bargagna S, Ciampi M, Sbrana B, Calcagno M, Ferretti G \& Marcheschi M. Increased risk for language deficit in motor skills in early children with congenital hypothyroidism. Journal of Endocrinological Investigation 199316 (Suppl 1) 100. 
5 Gottschalk B, Richman RA \& Lewandowski L. Subtle speech and motor deficits of children with congenital hypothyroid treated early. Developmental Medicine and Child Neurology 199436 216-220.

6 Kooistra L, Laane C, Vulsma T, Schellekens JMH, Van der Meere JJ \& Kalverboer AF. Motor and cognitive development in children with congenital hypothyroidism: a long term evaluation of the effects of neonatal treatment. Journal of Pediatrics 1994124 903-909.

7 Rochiccioli P, Alexandre F \& Roge B. Development neurologique des hypothyroidies neonatales. Archives Francaises de Pediatrie 198744 (Suppl 1) 721-724.

8 Rondanini GF, Cerabolini R, Ongari B, Focarile F, Bollati A \& Chiumello G. Ipotiroidismo congenito, nuove problematiche psicologiche legate alla precocità della diagnosi. Minerva Pediatrica $198739457-461$.

9 Rovet JF, Ehrlich R \& Sorbara D. Effect of thyroid hormone level on temperament in infants with congenital hypothyroidism detected by screening of neonates. Journal of Pediatrics 1989114 63-68.

10 Hulse J. Outcome for congenital hypothyroidism. Archives of Disease in Childhood 198459 23-30.

11 Rovet J, Ehrlich R \& Sorbara D. Intellectual outcome in children with fetal hypothyroidism. Journal of Pediatrics 1987110 700-704.

12 Murphy GH, Hulse JA, Smith I \& Grant DB. Congenital hypothyroidism: physiological and psychological factors in early development. Journal of Child Psychology and Psychiatry 199031 711-725.

13 Fuggle PW, Grant DB, Smith I \& Murphy G. Intelligence, motor skills, and behaviour at 5 years in early treated congenital hypothyroidism. European Journal of Pediatrics 1991150 570-574.

14 Glorieux J, Dussault JH \& Guy VV. Intellectual development at age 12 years of children with congenital hypothyroidism diagnosed by newborn screening. Journal of Pediatrics $1992121581-584$

15 Simons WF, Fuggle PW, Grant DB \& Smith I. Intellectual development at 10 years in early treated congenital hypothyroidism. Archives of Disease in Childhood 199471 232-234.

16 Rovet J \& Ehrilch R. Longterm effect of L-thyroxine therapy for congenital hypothyroidism. Journal of Pediatrics 1995126 380-386.

17 Derksen-Lubsen G \& Verkerk PH. Neuropsychological development in early treated congenital hypothyroidism: analysis of literature data. Pediatric Research 199639 561-566.

18 Bargagna S, Chiovato L, Dinetti D, Montanelli L, Giachetti C, Romolini E et al. Neuropsychological development in a child with early treated congenital hypothyroidism as compared with her unaffected identical twin. European Journal of Endocrinology 1997 136 100-104.

19 New England Congenital Hypothyroidism Collaborative. Elementary school performance of children with congenital hypothyroidism. Journal of Pediatrics 1990116 27-32.

20 Rovet J, Ehrlich R \& Altmann D. Psychoeducational outcome of children with early congenital hypothyroidism. Thyroid 19955 (Suppl 1) S-84.

21 Simons WF, Fuggle PW, Grant DB \& Smith I. Educational progress behaviour and motor skills at 10 years in early treated congenital hypothyroidism. Archives of Disease in Childhood 199777 219-222.

22 Tolicic I. Test di Naturità Scolastica. Firenze: Organizzazioni Speciali, 1970 .

23 Martini A. Le Difficoltà di Apprendimento della Lingua Scritta: Criteri di Diagnosi e Indirizzi di Trattamento. Del Cerro, 1995.

24 Milner B. Interhemispheric differences in the localization of psychological processes in man. British Medical Bulletin 197127 272-277.
25 Cornoldi C, Colpo G \& Gruppo MT. La Verifica dell'Apprendimento della Lettura. Firenze: Organizzazioni Speciali, 1992.

26 Soresi S, Corcione D \& Gruppo MT. Prove Oggettive di Matematica per la Scuola Elementare. Firenze: Organizzazioni Speciali, 1992.

27 Griffiths R. The Abilities of Babies. A study in Mental Measurement. Bucks, UK: Association for Research in Infant and Child Development, 1976.

28 Touwen BCL. Examination of the child with minor neurological dysfunction. In Clinics in Developmental Medicine, pp 123-165. Ed W Heckeman. London: Medical Books, 1979.

29 Bortolini U \& Fanzago F. L'analisi in tratti distintivi nei disturbi di articolazione. Acta Phonologica Latina 199012 34-40.

30 Chilosi AM, Cirpiani P, Fazzi B, Giorgi A \& Pfanner L. Test di Comprensione Grammaticale per Bambini. del Cerro, 1995.

31 American Psychiatric Association Diagnostic and Statistical Manual of Mental Disorders, edn 4. Washington DC: American Psychiatric Association, 1994.

32 Hammill DD. On defining learning disabilities: an emerging consensus. Journal of Learning Disabilities 1990 23 74-84.

33 Levi G. Epidemiologia e programmazione dei servizi di neuropsichiatria infantile. Neuropsichiatria Infantile $198111223-237$.

34 Dudley-Marling CC \& Edmiaston R. Social status of learning disabled children and adolescents: a review. Learning Disabilities Quarterly 19858 189-196.

35 Stevenson J \& Richman N. The prevalence of language delay in a population of three year old children and its association with general retardation. Developmental Medicine and Child Neurology $197626528-538$.

36 Silva PA, McGee RO \& Williams SM. Developmental language delay from three to seven years and its significance for low intelligence and reading difficulties at age seven. Developmental Medicine and Child Neurology 198725 783-793.

37 Levi G, Capozzi F, Fabrizi A \& Sechi E. Language disorders and prognosis for reading disabilities in developmental age. Perceptual and Motor Skills $1982541119-1122$.

38 Satz P, Taylor HG, Friel J \& Fletcher J. Some developmental and predictive precursors of reading disabilities: a six years follow-up. In Dyslexia, pp 231-266. Eds AZ Benton \& D Pearl. New York: Oxford University Press, 1978.

39 Marcheschi M, Bargagna S, Dinetti D, Giachetti C \& Romolini E. Dinamiche familiari e rischi evolutivi nell'ipotiroidismo congenito precocemente trattato. Psichiatria dell'Infanzia e dell'Adolescenza $1996639-18$.

40 Chiovato L, Giusti L, Tonacchera M, Ciampi M, Mammoli C, Lippi $\mathrm{F}$ et al. Evaluation of L-thyroxine replacement therapy in children with congenital hypothyroidism. Journal of Endocrinological Investigation $199114957-964$.

41 Tillotson SL, Fuggle PW, Smith I, Ades AE \& Grant DB. Relation between biochemical severity and intelligence in early treated congenital hypothyroidism: a threshold effect. British Medical Journal 1994309 440-445.

42 Salerno M, Di Maio S, Militerni R, Argenziano A, Valerio G \& Tenore A. Prognostic factors in the intellectual development at 7 years of age in children with congenital hypothyroidism. Journal of Endocrinological Investigation 199518 774-779.

43 Dubois J-M, Glorieux J, Richer F, Deal CL, Dussault JH \& Van Vliet G. Outcome of severe congenital hypothyroidism: closing the developmental gap with early high dose levothyroxine treatment. Journal of Clinical Endocrinology and Metabolism 1996 $81222-227$.

Received 7 August 1998

Accepted 19 January 1999 